\title{
GRAMD4 mimics p53 and mediates the apoptotic function of p73 at mitochondria
}

\author{
K John, V Alla, C Meier and BM Pützer \\ Cell Death and Differentiation (2012) 19, 552; doi:10.1038/cdd.2011.194
}

Correction to: Cell Death and Differentiation (2011) 18, 874-886; doi:10.1038/cdd.2010.153

It has come to our attention that the wrong western blot results for actin in the bottom panel of Figure $3 \mathrm{~b}$ and for COX4 in Figure 7c were inserted. The correct actin

b
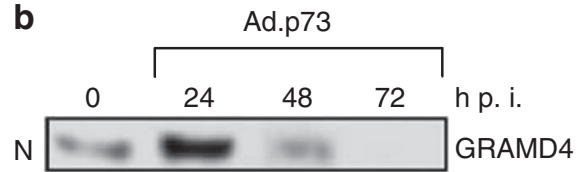

$\mathrm{N} \mathrm{p73}$

$\mathrm{N}=\mathrm{TBP}$
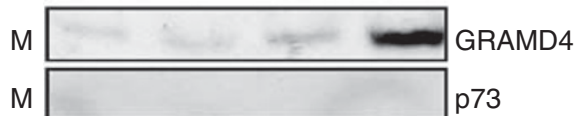

$\mathrm{M}$
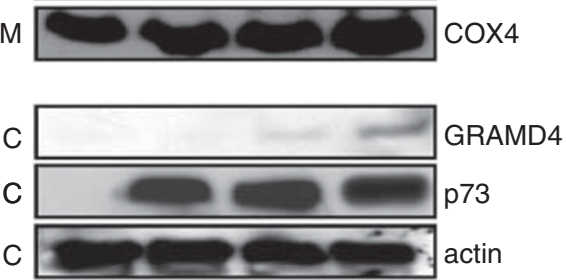

Figure 3 lane mislabeled as COX4 in the mitochondrial fraction (Ad.GRAMD4) of Figure 7c has been replaced. Appropriate figures are reproduced below.

The authors apologize for any confusion this might have caused.

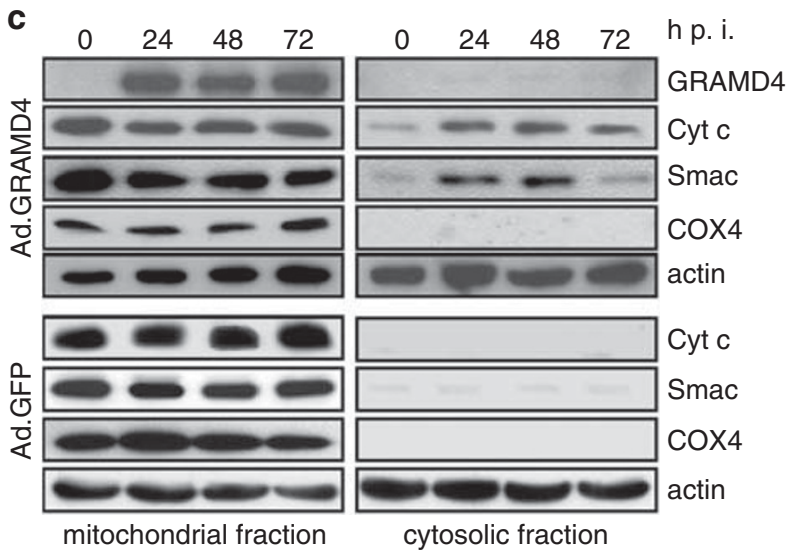

Figure 7 